\title{
Proton beam therapy and localised prostate cancer: current status and controversies
}

\author{
J A Efstathiou*,1, P J Gray ${ }^{1}$ and A L Zietman ${ }^{1}$ \\ ${ }^{1}$ Department of Radiation Oncology, Massachusetts General Hospital, Harvard Medical School, Boston, MA, USA
}

Proton therapy is a promising, but costly, treatment for prostate cancer. Theoretical physical advantages exist; yet to date, it has been shown only to be comparably safe and effective when compared with the alternatives and not necessarily superior. If clinically meaningful benefits do exist for patients, more rigorous study will be needed to detect them and society will require this to justify the investment of time and money. New technical advances in proton beam delivery coupled with shortened overall treatment times and declining device costs have the potential to make this a more cost-effective therapy in the years ahead.

Proton beam is a form of externally delivered radiation that has been in therapeutic use for over 40 years. The beam has certain unique physical attributes that make it particularly attractive for the treatment of cancer (Wilson, 1946). In particular the stream of positively charged subatomic particles enters tissue and deposits the bulk of its energy in the last few millimetres of the beam range. Tissue beyond this point receives very little radiation dose because of the absence of exit dose (Figure 1). It is upon this premise that the enthusiasm for proton beam therapy (PBT) has been built. The concept that tumours can be targeted with very little radiation being delivered to the adjacent normal tissues is particularly appealing, especially, when considering exquisitely sensitive normal tissues such as the brain stem, eye, spinal cord, or any tissue in a developing child. The promise of lowering morbidity and the risk of second radiation-induced cancers while, at the same time, escalating the cancer dose to more reliably eradicate the tumour has garnered justifiable enthusiasm.

Over the last two decades, PBT has developed much support for the treatment of paediatric cancers, and cancers of the eye, skull base, and spine. The early evidence of benefit was theoretical and came from simple demonstrations that normal tissues receive less radiation dose. The outcome benefits have, until recently, been presumed. New patient outcome data are emerging, showing, for example, a lower incidence of vision or hearing loss and improved neurocognitive function in paediatric cancers (MacDonald et al, 2008; Childs et al, 2012) and a lower incidence of second malignancies in paediatric cases overall (Miralbell et al, 2002; Chung et al, 2008).

Skull base and paediatric tumours are, however, rare, and when one considers the current cost for building a full 3-4 treatment room PBT cyclotron facility in the United States, up to
\$150-200 million, the question becomes is it worth the cost in an economic sense? (Pollack, 2007; Emanuel, 2012). For this reason, the manufacturers of proton beam equipment and several centres that have installed them may be looking at the more common cancers as a means of supporting the facilities. Prostate cancer has been a particular focus of attention and any patient who 'Googles' the term will rapidly arrive at proton beam as a highly advocated option (Shah et al, 2012a) leading to 'proton-seeking' behaviour. The hope exists that use of this technology will reduce the well-documented morbidity of prostate cancer treatment but outcome data studying its use has, until recently, been relatively thin. In the United States, prostate cancer has become one of the economic drivers for the establishment of new proton beam facilities, and this is the area where use of this technology is being most closely scrutinised by physicians and policy makers alike. It is on this area of controversy that our discussion will focus.

\section{THE PHYSICAL UNCERTAINTIES}

The physics of radiation therapy with a beam of proton particles has been well established, and attractive radiation dose-distribution maps can be generated that show highly conformal treatment delivery (Figure 2). Uncertainties do, however, exist and some of these pertain to the treatment of deep-seated tumours such as the prostate (Goitein, 2008). Although the beam can be stopped in tissue sharply over the first $10 \mathrm{~cm}$, at greater depths such as the depth of the average prostate gland, there is 'end-of-range uncertainty', and a penumbra develops laterally and around the distal end of the beam. This can blur the beam's sharp edge, 


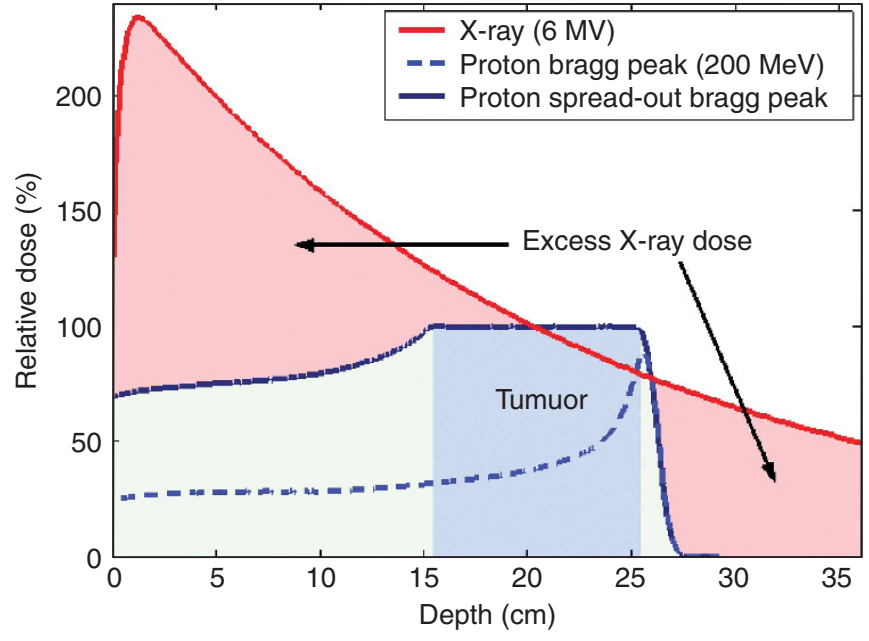

Figure 1. Radiation dose delivered at a certain depth in the body for a X-ray photon beam (red), the Bragg peak of an individual proton beam (dashed blue), and a spread-out Bragg peak combining multiple proton beams to cover the target (solid blue). The excess X-ray dose at entrance and at exit is highlighted.

delivering higher doses of radiation than anticipated to adjacent normal tissues. In addition, a proton beam is sensitive to tissue density and heterogeneity and may be perturbed by passage through very inhomogeneous tissue, such as bone, and then muscle of the pelvis. This becomes more of an issue if the bone is not fully immobilised as can be the case with the hips due to anatomical variation in femur angle (Trofimov et al, 2011). Similarly, targeting of dose can be affected significantly when organs move over the course of therapy (Wang et al, 2011). Protons may be associated with less scatter dose the further you get away from the prostate (Yoon et al, 2010) and consequently some modelling studies have reported lower rates of radiation-associated second cancers both in-field and out-of-field (Fontenot et al., 2009). However, neutrons may be produced and scattered from the heads of some types of proton treatment machines. The high radiobiological effect of neutrons has the risk of causing more secondary cancers than more conventional radiation treatment, thus potentially negating one of the putative advantages of the therapy (Brenner and Hall, 2008; Athar et al, 2010). Although efforts are underway to address some of the limitations associated with delivery of protons (Brenner et al, 2009; Tang et al, 2012), these physical uncertainties continue to generate much heated debate in the radiation oncology literature and are yet to be fully settled.

\section{THE CLINICAL EVIDENCE}

The management of localised prostate cancer has been a subject of debate for over 30 years. Surgery has improved in quality and proliferated in technique (open, laparoscopic, robotic assisted, and focal). Radiation therapy has done exactly the same (conventional 2-D, conformal 3-D, intensity-modulated radiation therapy (IMRT), stereotactic, and high- and low-dose brachytherapy). The majority of the radiation treatments for prostate cancer delivered in the United States today are given either by IMRT, a method that uses inhomogeneous photon beams of non-uniform intensity to sculpt around critical structures like the rectum, or brachytherapy, a procedure that involves the implantation of radioactive devices directly into the prostate. In addition, elegant modes of daily immobilisation and localisation of the prostate using image-guided radiation therapy techniques have been generally adopted. Of note, at this stage, modes of image guidance
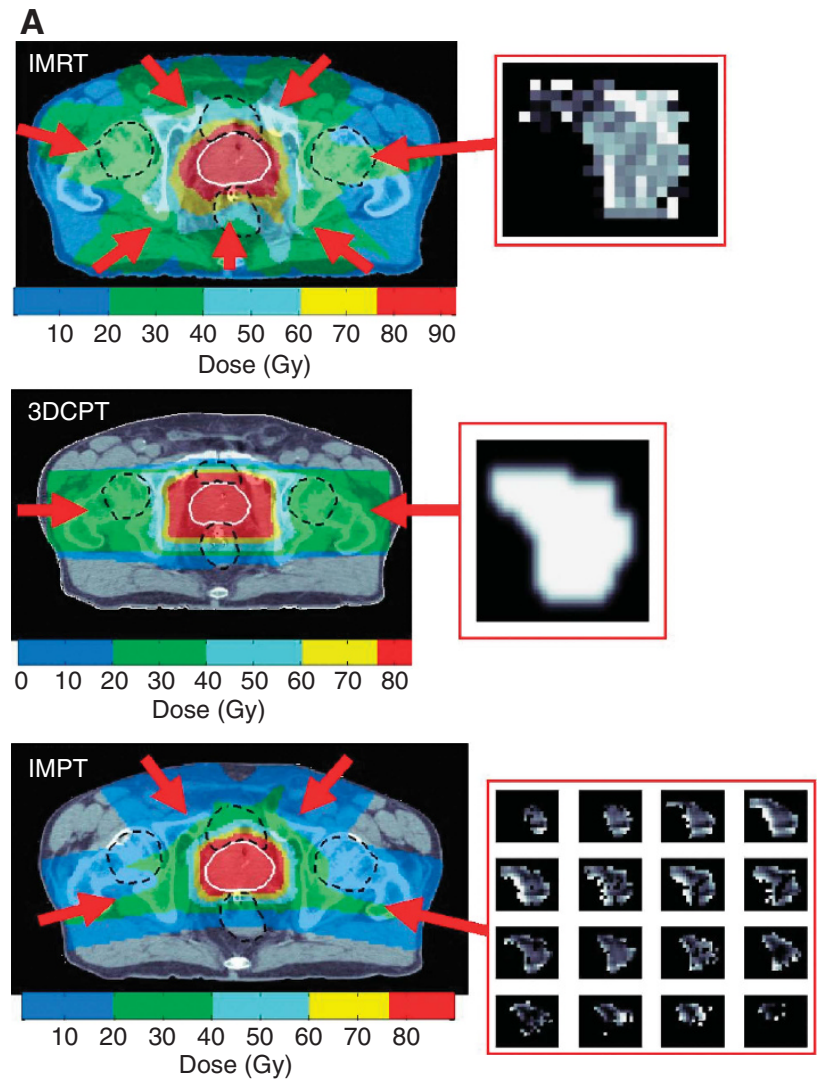

B

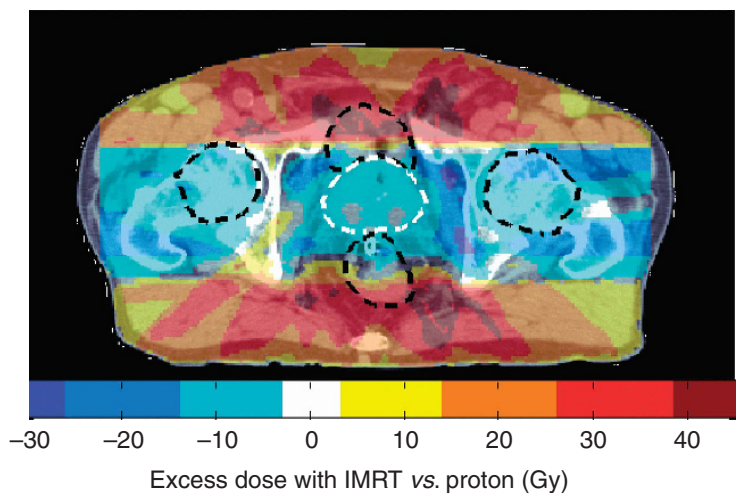

Figure 2. (A) With intensity-modulated radiation therapy (IMRT), between 5 and 9 inhomogeneous X-ray beams from different angles are used to conform the high radiation dose to the prostate. With 3-D conformal proton therapy (3DCPT), the dose is delivered with two lateral scattered beams shaped by apertures to create a uniform field. With intensity-modulated proton therapy (IMPT), dose is delivered by scanning a narrow pencil beam across the target in three dimensions, and modulating both the current and energy of the beam to yield dose distributions that are typically more conformal to the target than with 3DCPT. (B) When subtracting dose between proton and IMRT plans, one is left with an excess low-dose radiation bath over a larger region of the pelvis with IMRT.

(i.e., daily cone beam computed tomography or electromagnetic emitting transponders) are generally more advanced (and in fact more costly) for IMRT than proton beam. Although many studies have documented either increased rates of cancer eradication or better patient quality of life with modern techniques delivering contemporary high doses of radiation (Zelefsky et al, 2001; Sanda et al, 2008; Zietman et al, 2010a; Bekelman et al, 2011; Michalski et al, 2011), these have been rather modest improvements and 
there has been sparse high-quality evidence supporting one technology over another. Although, one randomised comparison did demonstrate a benefit to 2-D vs 3-D (Dearnaley et al, 1999), in general, there has been rapid and uncontrolled marketing, demand, dissemination, and implementation of new and promising technologies (both hardware and software) before their effectiveness and comparative value have been rigorously evaluated. The increased need for cost-control inevitably will demand higher levels of evidence supporting clinical efficacy and cost-effectiveness. The question remains whether or not proton beam with its current high price tag brings added value.

Only one randomised trial exists comparing conventional radiation therapy with proton beam, and this was initiated in the 1980s using older techniques and treating advanced disease in the era before early detection with PSA (Shipley et al, 1995). There was no difference in outcome between the two arms, but this study is now of historical interest only. Several studies comparing the dosimetry of proton beam with IMRT have been published and, depending upon the choice of beams and planning systems, IMRT can be seen as theoretically a little better or a little worse than protons (Trofimov et al, 2007; Vargas et al, 2008; Nihei et al, 2011). Our own work suggests that the conformity of dose distribution to the prostate may be better with IMRT. In the high-dose regions, IMRT shows better sparing of the bladder and rectal sparing is similar, whereas in the low-dose regions, proton beam achieves better sparing of both rectum and bladder (Trofimov et al, 2007). Thus, IMRT creates more of a low-dose radiation 'bath' over a larger region of the pelvis and leads to a higher, though still relatively small, whole-body radiation dose (Figure 2 ). This begs the question whether the worse morbidity of radiation therapy comes from the high-dose area (sexual, rectal, and bladder functions) or the cumulative low-dose areas (fatigue, bowel function, and second cancers). Dosimetric studies showing relatively modest differences in physical dose distribution are of little value without looking for measurable and meaningful differences in clinical outcome. Although radiation oncologists have been eager to adopt proton beam for prostate cancer, they have been slow to perform clinical studies. This is now being addressed. Recent prospective clinical studies have documented certain truths about proton beam and prostate cancer.

First, that radiation dose escalation to the prostate may be safely achieved. We have shown that patient-reported quality of life is the same at doses of either 70 or $79 \mathrm{~Gy}$ when the boost dose is delivered by protons (Talcott et al, 2010). This does not, however, address the fact that escalation to the same doses may be achieved and be equally well tolerated by other radiation techniques like IMRT or brachytherapy. That is to say that, despite the theoretical physical advantages of proton therapy, studies have yet to show any clear clinical benefit to proton beam over IMRT in terms of morbidity in the treatment of prostate cancer. No direct head-tohead comparison between the two has yet been done, although a multicenter randomised trial has recently been launched (discussed below). Talcott et al (2010) did make comparisons between two separate, though contemporary, cohorts of patients treated with proton beam or either IMRT or 3-D conformal therapy and found no overt differences. The principal concerns of patients, erectile dysfunction, voiding dysfunction, and rectal dysfunction, appear to occur with similar acceptably low frequency. We have generated some preliminary data suggesting transient differences in toxicity patterns with a potential early short-term, though time-limited, improvement in bowel and urinary symptoms with PBT vs IMRT (Gray et al, 2013). New data from other US proton centers are also demonstrating excellent quality of life outcomes and low rates of significant early gastrointestinal and genitourinary toxicity, with proton-based therapy for prostate cancer, although these may come from the use of prostate immobilisation and image guidance as much as from the use of proton beam (Mendenhall et al, 2012).
Two other recent studies, however, have suggested that PBT is associated with increased bowel toxicity compared with IMRT (Kim et al, 2011; Sheets et al, 2012). These studies rely on billing codes that may not capture the patient's own experience and large databases that contain few PBT patients and also lack data on treatment dose, margins, and other important relevant clinical factors. As such, the validity of these conclusions remains a matter of debate. It is also worth noting that the follow-up from all of these studies is too short to capture all the late effects of radiation, which may continue to accumulate at 10 years or beyond (Gardner et al, 2002).

Second, that cancer-control rates after proton beam are as good as those obtained with any other kind of radiation therapy (Zietman et al, 2010a). Proton beam is certainly an effective addition to the armamentarium. Although there are no completed randomised trials, there is one recent case-matched comparison that shows identical cancer-control rates between proton beam and brachytherapy (Coen et al, 2012). Given that there is no evidence that proton beam is superior to other therapies in terms of prostate cancer control, it might be an improved (and more costly) means to an unimproved end.

Third, that using current proton delivery methods (passively scattered beams), radiation dose cannot be escalated significantly higher to achieve better cancer-control rates. A prospective study performed at the MGH and Loma Linda Medical Centre concluded that morbidity reaches the limits of acceptability at $82 \mathrm{~Gy}$, with rectal bleeding becoming a dose-limiting toxicity (Coen et al, 2011).

\section{COST AND USAGE}

Although these data supporting the efficacy of PBT continue to emerge, much attention has also focused on the cost of PBT relative to existing technologies. The number of centres offering proton therapy in the United States is expected to double in the next 3 years (Johnson, 2012), and prostate cancer patients may represent up to $75 \%$ of the future consumers at these centres (Jarosek et al, 2011). An analysis using Markov models informed by cost and efficacy data was conducted to compare the costeffectiveness of $91.8 \mathrm{~Gy}$ (RBE) delivered with proton beam to $81 \mathrm{~Gy}$ delivered with IMRT. It was assumed that this $10 \mathrm{~Gy}$ dose escalation would result in a survival advantage without an increase in toxicity, though this remains debatable as previously discussed (Coen et al, 2011). Despite this assumption, the incremental costeffectiveness ratio for PBT was calculated to be $\$ 63578$ per QALY for a 70 -year-old man and $\$ 55726$ per QALY for a 60 -year-old man. Using the commonly accepted standard of $\$ 50000$ per quality-adjusted life year, PBT did not appear to be cost-effective (Konski et al, 2007). Other economic reviews have found the lifetime cost for treatment, follow-up, and management of recurrence and side effects to be $\$ 53828$ for PBT, $\$ 37861$ for IMRT, \$25484 for brachytherapy, \$28348 for radical prostatectomy, and \$30 422 for active surveillance (Ollendorf et al, 2009). The exact degree of the incremental increase in cost for PBT over IMRT remains a subject of debate, however. One recent study suggested the median amount reimbursed by the US Medicare insurance program was $\$ 32428$ for PBT and $\$ 18575$ for IMRT (Yu et al, 2013). There are clear ranges of costs that are billed and reimbursed depending on provider and payer, and ways in which cost is modelled, highlighting that pricing considerations remain a moving target, and these will adapt and be fluid in the era of health-care payment reform.

Two future trends may, however, reduce the cost of proton beam delivery and make it a more competitive option for patients. First, several randomised and other trials (Kupelian et al, 2007; Boike et al, 2011; Arcangeli et al, 2012; Dearnaley et al, 2012) have 
published early results suggesting safety and equivalence between conventional fractionation and hypo-fractionation (i.e., shorter treatment regimens that deliver fewer larger fractions of radiation that may offer a therapeutic gain) in prostate cancer, and proton beam is being investigated in this manner (Radiation Therapy Oncology Group protocol 0938). As the cost of treatment delivery in the United States is proportional to the number of fractions given, this alone may not only lead to cost savings but also better resource allocation and increased patient convenience. Indeed, decreasing the total number of fractions delivered from 44 to 28 or as few as 5, could result in a significant reduction in the incremental cost difference of PBT. The second is that there is a natural trend towards simplification and streamlining of any technology as it matures. New single gantry facilities are being developed with a \$15-25 million price tag. Although this still remains costlier than most other medical technologies (for example a linear accelerator capable of delivering IMRT may cost \$1-5 million), the debt incurred may be managed without requiring such high patient throughput and high treatment charges. As further technical advances and operational efficiencies are employed, further lowering of the cost gap between proton- and photon-based techniques will likely occur.

\section{THE FUTURE}

Proton beam therapy has not yet reached its full potential. The use of spot-scanned delivery is being adopted, and this technique allows for greater intensity modulation (Figure 2). Together with the use of more creative beam angles, conformality should be taken to new heights (Trofimov et al, 2007; Tang et al, 2012). It remains debatable, however, whether or not this will translate into fewer side effects and/or allow the delivery of higher doses to the prostate as most of the morbidity comes from irradiation of the prostatic urethra, bladder neck, anterior rectum, and nerves. These tissues are either within the prostate or immediately adjacent to it and are unlikely to be significantly further spared without undertreating the prostate itself. Focal or partial prostate therapy is being examined for very early cancers using focused ultrasound or cryotherapy, and it is possible that intensity-modulated protons could have a similar role. Alternatively, protons could be used to deliver partial prostate boosts in the case of more advanced cancer (Figure 3 ).

If PBT were exactly the same cost as other forms of external radiation, there may be less of a discussion. It would simply be regarded as another arrow in the quiver of radiation options with potential theoretical benefits. It is, however, the powerful advocacy for its superiority ahead of rigorous evidence that attracts suspicion. In this way, PBT is illustrative of a broad problem in medicine generally. How can promising new and emerging technologies that are rapidly evolving be evaluated in a rigorous and sufficiently timely fashion such that creativity and innovation are not stifled? The vast majority of new technologies are incremental advances of existing techniques that do not require testing beyond that of basic safety as mandated by governmental regulatory bodies. Alternative methodologies such as prospective observational registries (as has been done for PET scanning and cardiac devices) may be employed to assess efficacy and appropriate utilisation. For a few technologies, however, and proton beam is arguably one of them, there has not been a simple incremental evolution but a gigantic revolution. It is here that randomised controlled trials (RCTs) may still have a role, and the earlier they are initiated the better (Zietman et al, 2010b). It has been argued that the RCT remains crucial when: the new technology introduces a new biology; when retraining or recredentialing is required; when the technology is as likely to be less effective as it is more effective than the alternatives; or when the

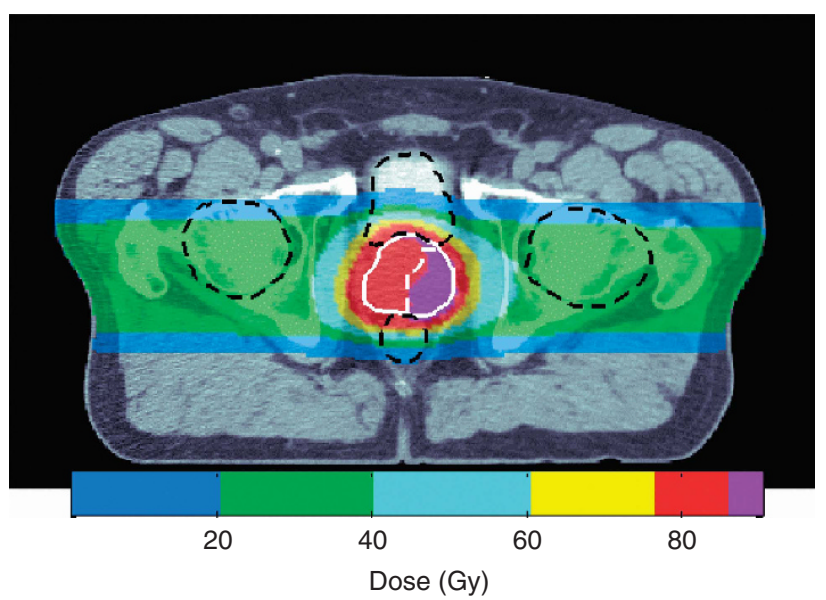

Figure 3. Use of diagnostic imaging, image guidance, and sharper beams with intensity-modulated proton therapy (IMPT) to deliver nonuniform focal boost doses (i.e., $>80 \mathrm{~Gy}$ ) to part of the prostate (purple-colour wash).

technology carries such a price that it will alter the resources available to care for others. Proton beam meets several of these criteria. The relative radiobiological effectiveness is not known with absolute accuracy for different tissues, and this may matter when ultra-high doses are being delivered (Carabe-Fernandez et al, 2011). For this reason, and because of the differences in dose distribution between protons and IMRT, there are circumstances where the outcome may be worse and not necessarily better.

A RCT is, however, not necessary for every disease or every site to be treated by protons. It is clear, for example, that there will be little advantage to treating superficial skin cancers this way. Equally, there would be few willing to randomise paediatric patients because the theoretical advantages of proton beam are so great and the consequences of more conventional treatment so devastating that therapeutic equipoise, a central requirement of any RCT, could not be assumed (Hellman and Hellman, 1991). Furthermore, a RCT would be impractical for rare indications (such as skull base chordomas) or when patients are unwilling to be randomised (van Loon et al, 2012). As such, RCTs should be reserved for the 'grey zones', such as prostate cancer, where we need to document not only efficacy and safety (done already) but to quantitate value added. Patients have indicated their willingness to participate in such a trial for prostate cancer (Shah et al, 2012b). Several major US proton centers led by the Massachusetts General Hospital and University of Pennsylvania have recently launched a phase III randomised trial of IMRT vs PBT for localised low and low-intermediate risk prostate cancer (http://clinicaltrials.gov/ct2/ show/NCT01617161), with patient-reported quality of life outcomes, as well as other clinical, physical, biological, and economic end points (including assessing cost-effectiveness under current and future conditions for alternative treatment delivery and pricing scenarios). Events are moving too fast, and the answers this trial will provide cannot come too soon.

\section{ACKNOWLEDGEMENTS}

We are thankful to Alexei Trofimov, $\mathrm{PhD}$, and Hsiao-Ming Lu, $\mathrm{PhD}$, for their assistance with graphics.

\section{CONFLICT OF INTEREST}

The authors declare no conflict of interest. 


\section{REFERENCES}

Arcangeli S, Strigari L, Gomellini S, Saracino B, Petrongari MG, Pinnaro P, Pinzi V, Arcangeli G (2012) Updated results and patterns of failure in a randomized hypofractionation trial for high-risk prostate cancer. Int $J$ Radiat Oncol Biol Phys 84: 1172-1178.

Athar BS, Bednarz B, Seco J, Hancox C, Paganetti H (2010) Comparison of out-of-field photon doses in 6MV IMRT and neutron doses in proton therapy for adult and pediatric patients. Phys Med Biol 55: 2879-2891.

Bekelman JE, Mitra N, Efstathiou J, Liao K, Sunderland R, Yeboa DN, Armstrong K (2011) Outcomes after intensity-modulated versus conformal radiotherapy in older men with nonmetastatic prostate cancer. Int J Radiat Oncol Biol Phys 81: e325-e334.

Boike TP, Lotan Y, Cho LC, Brindle J, DeRose P, Xie XJ, Yan J, Foster R, Pistenmaa D, Perkins A, Cooley S, Timmerman R (2011) Phase I doseescalation study of stereotactic body radiation therapy for low- and intermediate-risk prostate cancer. J Clin Oncol 29: 2020-2026.

Brenner DJ, Elliston CD, Hall EJ, Paganetti H (2009) Reduction of the secondary neutron dose in passively scattered proton radiotherapy, using an optimized pre-collimator/collimator. Phys Med Biol 54: 6065-6078.

Brenner DJ, Hall EJ (2008) Secondary neutrons in clinical proton radiotherapy: a charged issue. Radiother Oncol 86: 165-170.

Carabe-Fernandez A, Paganetti H (2011) Clinical consequences of relative biological effectiveness (RBE) variations in proton radiotherapy of the prostate, brain, and liver. Int J Radiat Oncol Biol Phys 81: S725-S726.

Childs SK, Kozak KR, Friedmann AM, Yeap BY, Adams J, MacDonald SM, Liebsch NJ, Tarbell NJ, Yock TI (2012) Proton radiotherapy for parameningeal rhabdomyosarcoma: clinical outcomes and late effects. Int J Radiat Oncol Biol Phys 82: 635-642.

Chung CS, Keating N, Yock TI, Tarbell NJ (2008) Comparative analysis of secondary malignancy risk in patients treated with proton therapy versus conventional photon therapy. Int J Radiat Oncol Biol Phys 72: S8.

Coen JJ, Bae K, Zietman AL, Patel B, Shipley WU, Slater JD, Rossi CJ (2011) Acute and late toxicity after dose escalation to $82 \mathrm{GyE}$ using conformal proton radiation for localized prostate cancer: initial report of American College of Radiology Phase II study 03-12. Int J Radiat Oncol Biol Phys 81: 1005-1009.

Coen JJ, Zietman AL, Rossi CJ, Grocela JA, Efstathiou JA, Yan Y, Shipley WU (2012) Comparison of high-dose proton radiotherapy and brachytherapy in localized prostate cancer: a case-matched analysis. Int J Radiat Oncol Biol Phys 82: e25-e31.

Dearnaley D, Syndikus I, Sumo G, Bidmead M, Bloomfield D, Clark C, Gao A, Hassan S, Horwich A, Huddart R, Khoo V, Kirkbride P, Mayles H, Mayles P, Naismith O, Parker C, Patterson H, Russell M, Scrase C, South C, Staffurth J, Hall E (2012) Conventional versus hypofractionated high-dose intensity-modulated radiotherapy for prostate cancer: preliminary safety results from the CHHiP randomised controlled trial. Lancet Oncol 13: 43-54.

Dearnaley DP, Khoo VS, Norman AR, Meyer L, Nahum A, Tait D, Yarnold J, Horwich A (1999) Comparison of radiation side-effects of conformal and conventional radiotherapy in prostate cancer: a randomised trial. Lancet 353: $267-272$.

Emanuel EJ, Pearson SD (2012) Is costs more, but is it worth more? The New York Times, 2 January 2012.

Fontenot JD, Lee AK, Newhauser WD (2009) Risk of secondary malignant neoplasms from proton therapy and intensity-modulated $\mathrm{x}$-ray therapy for early-stage prostate cancer. Int J Radiat Oncol Biol Phys 74: 616-622.

Gardner BG, Zietman AL, Shipley WU, Skowronski UE, McManus P (2002) Late normal tissue sequelae in the second decade after high dose radiation therapy with combined photons and conformal protons for locally advanced prostate cancer. J Urol 167: 123-126.

Goitein M (2008) Magical protons? Int J Radiat Oncol Biol Phys 70: 654-656.

Gray PJ, Paly JJ, Yeap BY, Sanda MG, Sandler HM, Michalski JM, Talcott JA, Coen JJ, Hamstra DA, Shipley WU, Hahn SM, Zietman AL, Bekelman JE, Efstathiou JA (2013) Patient-reported outcomes following 3-dimensional conformal, intensity-modulated or proton beam radiotherapy for localized prostate cancer. Cancer; e-pub ahead of print 22 February 2013; doi:10.1002/cncr.27956.

Hellman S, Hellman DS (1991) Of mice but not men. Problems of the randomized clinical trial. $N$ Engl J Med 324: 1585-1589.
Jarosek S, Elliott S, Virnig BA (2011) Proton beam radiotherapy in the U.S. Medicare population: growth in use between 2006 and 2009: Data Points \# 10. 2012 May 7. In: Data Points Publication Series [Internet]. Rockville (MD): Agency for Healthcare Research and Quality (US). Available from: http:// www.ncbi.nlm.nih.gov/books/NBK97147/.

Johnson CY (2012) Proton beams vs. radiation. The Boston Globe, 14 May 2012.

Kim S, Shen S, Moore DF, Shih W, Lin Y, Li H, Dolan M, Shao YH, Lu-Yao GL (2011) Late gastrointestinal toxicities following radiation therapy for prostate cancer. Eur Urol 60: 908-916.

Konski A, Speier W, Hanlon A, Beck JR, Pollack A (2007) Is proton beam therapy cost effective in the treatment of adenocarcinoma of the prostate? $J$ Clin Oncol 25: 3603-3608.

Kupelian PA, Willoughby TR, Reddy CA, Klein EA, Mahadevan A (2007) Hypofractionated intensity-modulated radiotherapy (70 Gy at 2.5 Gy per fraction) for localized prostate cancer: Cleveland Clinic experience. Int $J$ Radiat Oncol Biol Phys 68: 1424-1430.

MacDonald SM, Safai S, Trofimov A, Wolfgang J, Fullerton B, Yeap BY, Bortfeld T, Tarbell NJ, Yock T (2008) Proton radiotherapy for childhood ependymoma: initial clinical outcomes and dose comparisons. Int $J$ Radiat Oncol Biol Phys 71: 979-986.

Mendenhall NP, Li Z, Hoppe BS, Marcus Jr. RB, Mendenhall WM, Nichols RC, Morris CG, Williams CR, Costa J, Henderson R (2012) Early outcomes from three prospective trials of image-guided proton therapy for prostate cancer. Int J Radiat Oncol Biol Phys 82: 213-221.

Michalski JM, Yan Y, Watkins-Bruner D, Walter B, Winter K, Galvin JM, Bahary J, Morton GC, Parliament MB, Sandler H (2011) Preliminary analysis of 3D-CRT vs. IMRT on the high dose arm of the rtog 0126 prostate cancer trial: toxicity report. Int J Radiat Oncol Biol Phys 81: S1-S2.

Miralbell R, Lomax A, Cella L, Schneider U (2002) Potential reduction of the incidence of radiation-induced second cancers by using proton beams in the treatment of pediatric tumors. Int J Radiat Oncol Biol Phys 54: 824-829.

Nihei K, Ogino T, Onozawa M, Murayama S, Fuji H, Murakami M, Hishikawa Y (2011) Multi-institutional phase II study of proton beam therapy for organ-confined prostate cancer focusing on the incidence of late rectal toxicities. Int J Radiat Oncol Biol Phys 81: 390-396.

Ollendorf DA, Hayes J, McMahon P, Kuba M, Pearson SD (2009) Management Options for Low-Risk Prostate Cancer: A Report On Comparative Effectiveness And Value. Institute for Clinical and Economic Review: Boston, MA, USA.

Pollack A (2007) Cancer fight goes nuclear, with heavy price tag. The New York Times, 26 December 2007.

Sanda MG, Dunn RL, Michalski J, Sandler HM, Northouse L, Hembroff L, Lin X, Greenfield TK, Litwin MS, Saigal CS, Mahadevan A, Klein E, Kibel A, Pisters LL, Kuban D, Kaplan I, Wood D, Ciezki J, Shah N, Wei JT (2008) Quality of life and satisfaction with outcome among prostatecancer survivors. N Engl J Med 358: 1250-1261.

Shah A, Paly JJ, Efstathiou JA, Bekelman JE (2012a) Physician Evaluation of Internet Health Information on Proton Therapy for Prostate Cancer. Int J Radiat Oncol Biol Phys; doi:pii: S0360-3016(12)03739-X. 10.1016/ j.ijrobp.2012.10.039.

Shah A, Efstathiou JA, Paly JJ, Halpern SD, Bruner DW, Christodouleas JP, Coen JJ, Deville Jr. C, Vapiwala N, Shipley WU, Zietman AL, Hahn SM, Bekelman JE (2012b) Prospective preference assessment of patients' willingness to participate in a randomized controlled trial of intensitymodulated radiotherapy versus proton therapy for localized prostate cancer. Int J Radiat Oncol Biol Phys 83: e13-e19.

Sheets NC, Goldin GH, Meyer AM, Wu Y, Chang Y, Sturmer T, Holmes JA, Reeve BB, Godley PA, Carpenter WR, Chen RC (2012) Intensitymodulated radiation therapy, proton therapy, or conformal radiation therapy and morbidity and disease control in localized prostate cancer. JAMA 307: 1611-1620.

Shipley W, Verhey L, Munzenrider J, Suit HD, Urie MM, McManus PL, Young RH, Shipley JW, Zietman AL, Biggs PJ, Heney NM, Goitein M (1995) Advanced prostate cancer: the results of a randomized comparative trial of high dose irradiation boosting with conformal protons compared with conventional dose irradiation using photons alone. Int J Radiat Oncol Biol Phys 30: 3-12.

Talcott JA, Rossi C, Shipley WU, Clark JA, Slater JD, Niemierko A, Zietman AL (2010) Patient-reported long-term outcomes after conventional and high-dose combined proton and photon radiation for early prostate cancer. JAMA 303: 1046-1053. 
Tang S, Both S, Bentefour H, Paly JJ, Tochner Z, Efstathiou J, Lu HM (2012) Improvement of prostate treatment by anterior proton fields. Int $J$ Radiat Oncol Biol Phys 83: 408-418.

Trofimov A, Nguyen PL, Coen JJ, Doppke KP, Schneider RJ, Adams JA, Bortfeld TR, Zietman AL, Delaney TF, Shipley WU (2007) Radiotherapy treatment of early-stage prostate cancer with IMRT and protons: a treatment planning comparison. Int J Radiat Oncol Biol Phys 69: 444-453.

Trofimov A, Nguyen PL, Efstathiou JA, Wang Y, Lu HM, Engelsman M, Merrick S, Cheng CW, Wong JR, Zietman AL (2011) Interfractional variations in the setup of pelvic bony anatomy and soft tissue, and their implications on the delivery of proton therapy for localized prostate cancer. Int J Radiat Oncol Biol Phys 80: 928-937.

van Loon J, Grutters J, Macbeth F (2012) Evaluation of novel radiotherapy technologies: what evidence is needed to assess their clinical and cost effectiveness, and how should we get it? Lancet Oncol 13: e169-e177.

Vargas C, Fryer A, Mahajan C, Indelicato D, Horne D, Chellini A, McKenzie C, Lawlor P, Henderson R, Li Z, Lin L, Olivier K, Keole S (2008) Dosevolume comparison of proton therapy and intensity-modulated radiotherapy for prostate cancer. Int J Radiat Oncol Biol Phys 70: 744-751.

Wang Y, Efstathiou JA, Sharp GC, Lu HM, Ciernik IF, Trofimov AV (2011) Evaluation of the dosimetric impact of interfractional anatomical variations on prostate proton therapy using daily in-room CT images. Med Phys 38: 4623-4633.
Wilson RR (1946) Radiological use of fast protons. Radiology 47: 487-491.

Yoon M, Ahn SH, Kim J, Shin DH, Park SY, Lee SB, Shin KH, Cho KH (2010) Radiation-induced cancers from modern radiotherapy techniques: intensity-modulated radiotherapy versus proton therapy. Int $J$ Radiat Oncol Biol Phys 77: 1477-1485.

Yu JB, Soulos PR, Herrin J, Cramer LD, Potosky AL, Roberts KB, Gross CP (2013) Proton versus intensity-modulated radiotherapy for prostate cancer: patterns of care and early toxicity. J Natl Cancer Inst 105: 25-32.

Zelefsky MJ, Fuks Z, Hunt M, Lee HJ, Lombardi D, Ling CC, Reuter VE, Venkatraman ES, Leibel SA (2001) High dose radiation delivered by intensity modulated conformal radiotherapy improves the outcome of localized prostate cancer. J Urol 166: 876-881.

Zietman A, Tepper J, Goitein M (2010b) Technology evolution: is it survival of the fittest? J Clin Oncol 28: 4275-4279.

Zietman AL, Bae K, Slater JD, Shipley WU, Efstathiou JA, Coen JJ, Bush DA, Lunt M, Spiegel DY, Skowronski R, Jabola BR, Rossi CJ (2010a) A randomized trial comparing conventional dose conformal radiation therapy with high-dose in early stage adenocarcinoma of the prostate. Long-term results from Proton Radiation Oncology Group (PROG)/American College of Radiology (ACR) 95-09. J Clin Oncol 28: 1106-1111. 